\title{
receptionist survey:
}

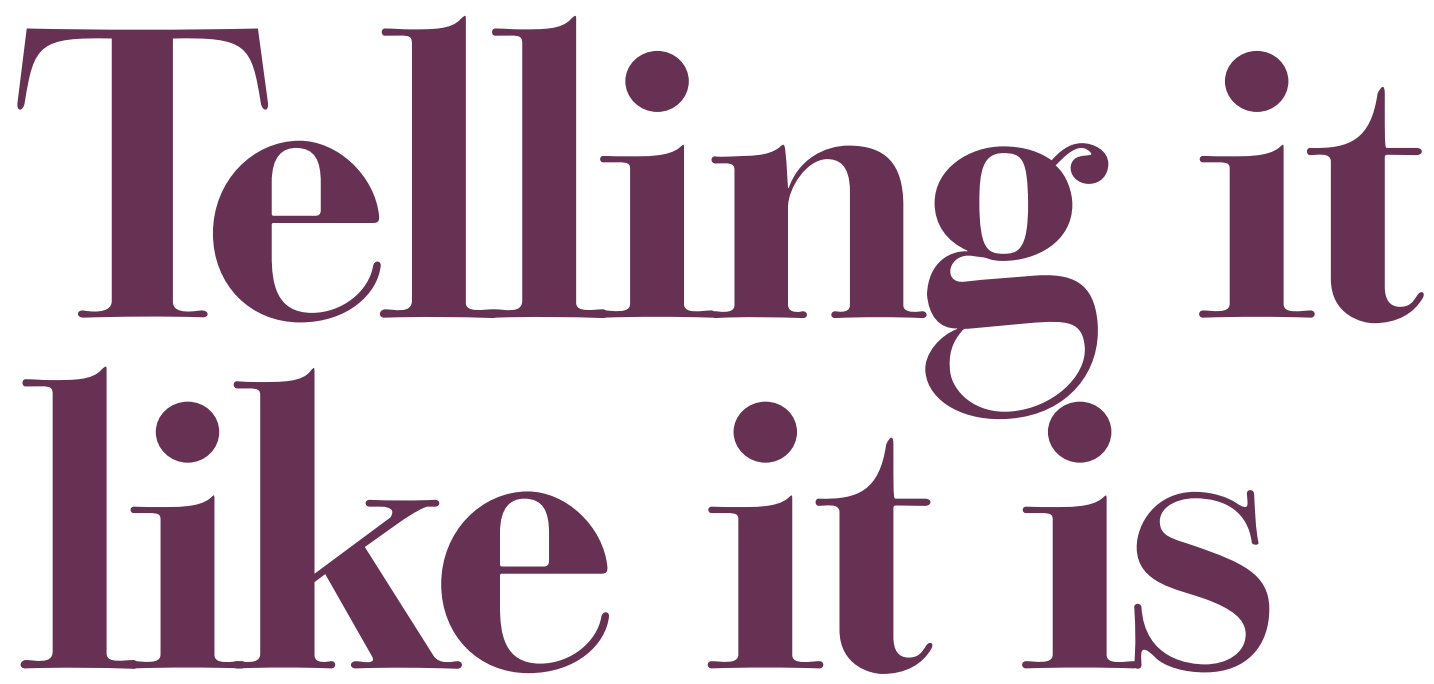

Throughout 2003 the British Dental Receptionists' Association surveyed its members to establish a profile for dental receptionists in the UK.

10,000 forms were circulated early in 2003 and nearly 1,000 responses were received, a response rate
of 10 per cent. Not every respondent answered every question, which means not all questions are
based on 1000 responses, and the BDRA reports that in some cases the results simply raised further
questions. Despite these limitations, Vital feels the results are worth publishing, as the BDRA feels
they provide an insight into the role played by the dental receptionist.
A summary of the results is presented below:

\section{Gender of receptionists}

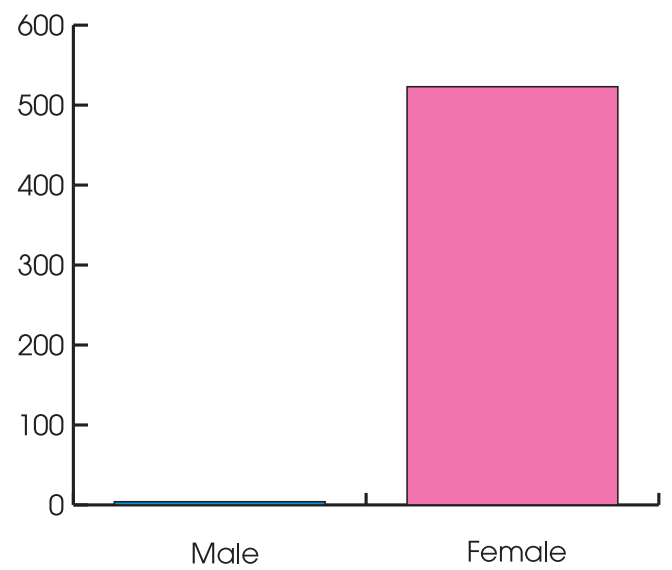

Gender breakdown of respondents

BDRA comment: There were no male responses from Scotland and only four from England and Wales, an unsurprising result.

\section{Age of receptionists}

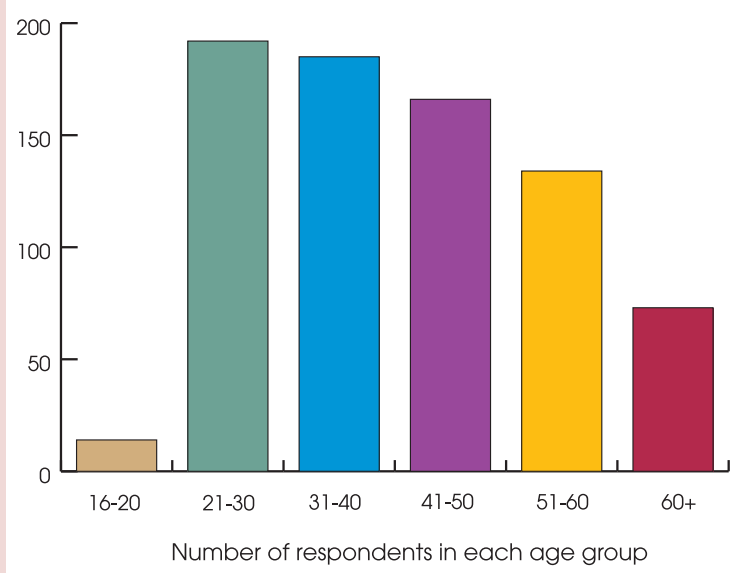

BDRA comment: Very few responses were from 16-20 year olds; the youngest receptionist population was in London, elsewhere the average age was much older. 


\section{receptionist survey}

\section{Ratio}

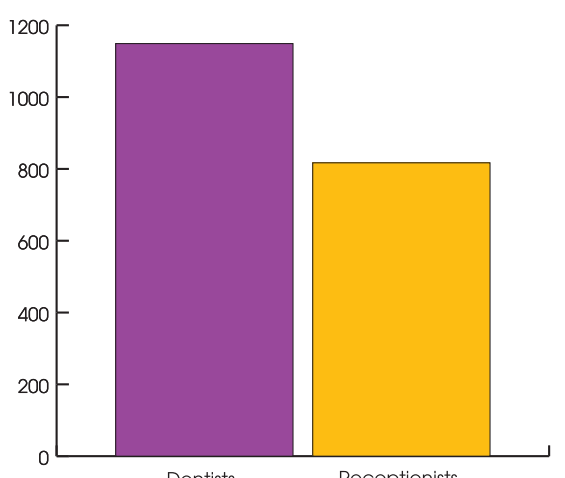

Dentists

Receptionists

Ratio of dentists to receptionists in England and Wales

BDRA comment: In England and Wales 817 receptionists were working with 1149 dentists.

\section{Work duties}

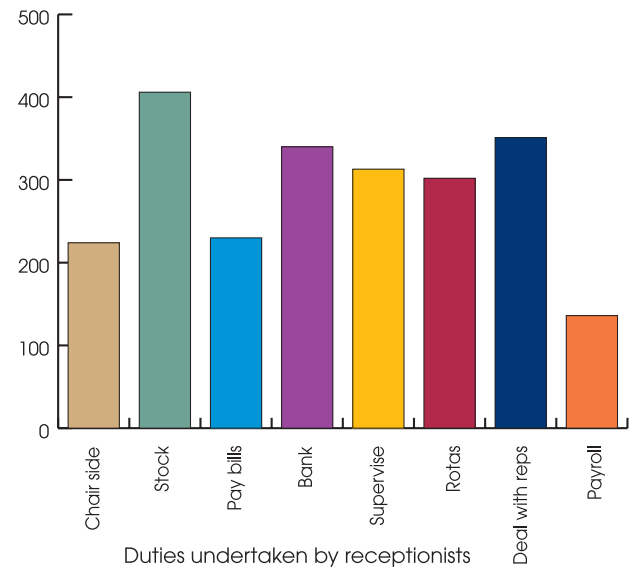

BDRA comment: $90 \%$ of receptionists are responsible for stock control and dealing with reps and over 50\% had responsibility for supervising other staff.

\section{Pay}

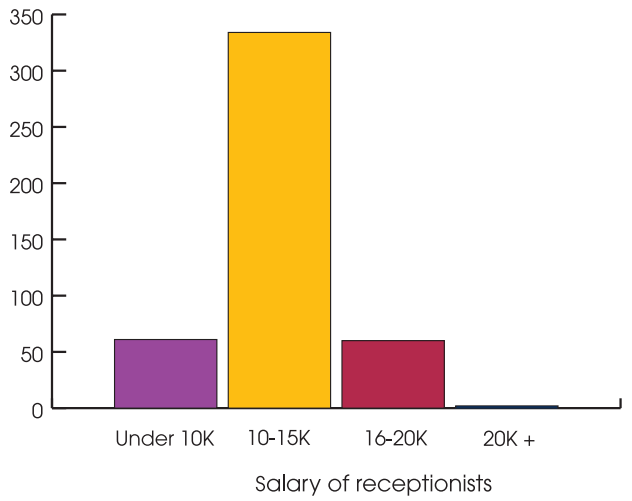

BDRA comment: Most responses were in the $£ 10,000-£ 15,000$ pay range. The lowest paid were in Scotland, the highest in England but surprisingly not London.

\section{Opening hours}

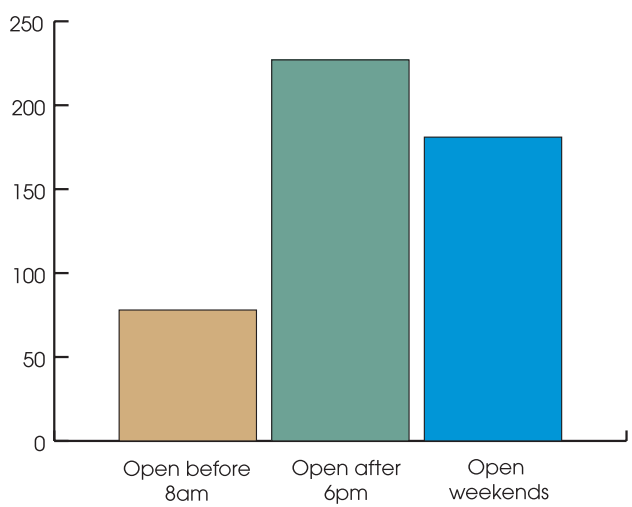

Number of practices open in each time bracket

BDRA comment: Few practices opened before $8 a m$ - those that did were in London. Fifty per cent of practices open after $6 \mathrm{pm}$, and $25 \%$ at weekends.

\section{Hours worked}

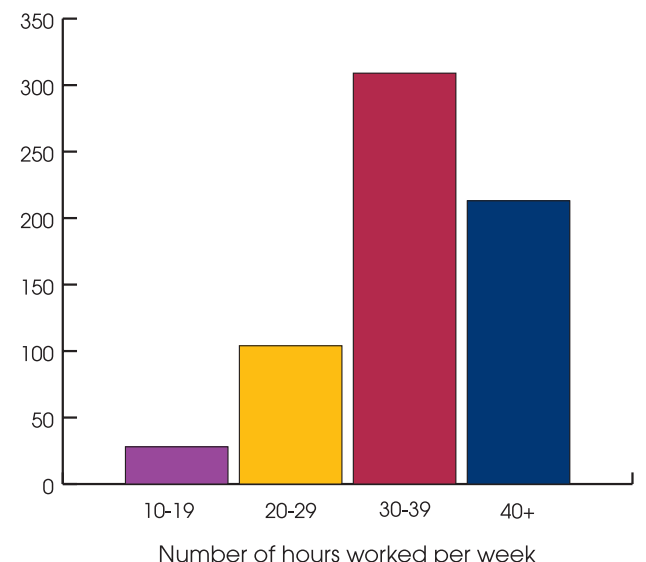

BDRA comment: Receptionists are much more likely to work more than 30 hours per week than to work part-time.

\section{Qualifications}

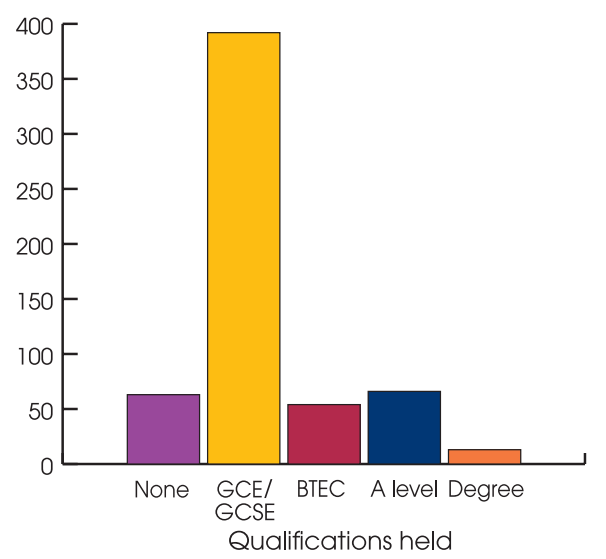

BDRA comment: The vast majority of respondents are qualified to GCE/GCSE standard. 


\section{receptionist survey:}
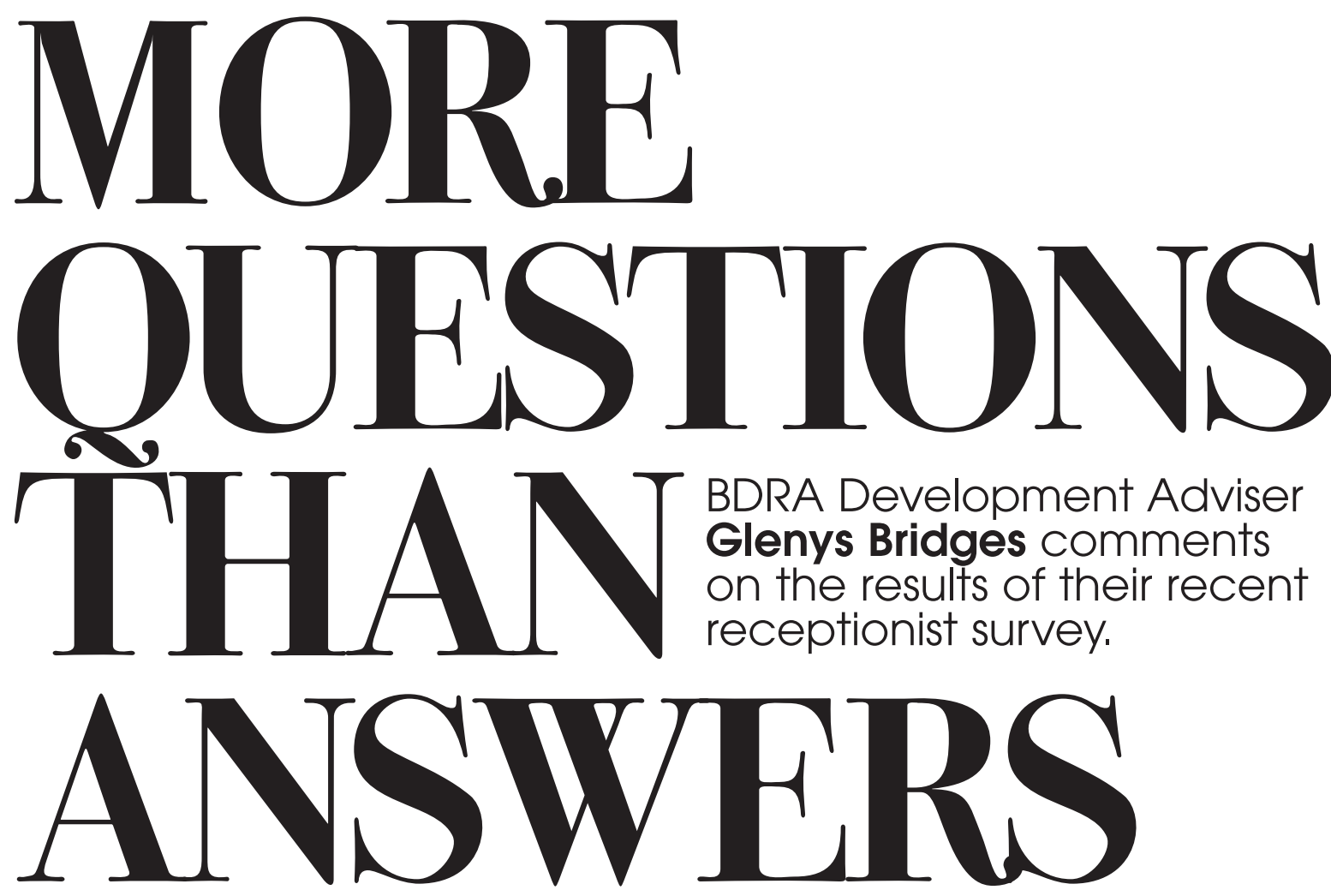

When the BDRA was established we stated our aims to be:

> Promote the role of receptionist

$>$ Represent receptionists within the profession

> Facilitate professional development

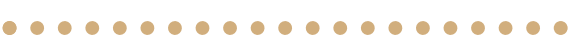

The 2003 BDRA Survey was developed to enable the Association to recognise how to go about fulfilling our agenda. Firstly, we needed to know what our members need from us. Each member of the BDRA committee has worked on the front desk in general dental practice. We have between us many years of dental practice experience, however we needed to produce a national picture and formal evidence that our own experiences were typical. The survey results are a sound basis for us to set out our agen$\mathrm{da}$ for supporting and providing professional opportunities for our members.

The majority of responses fitted well within our expectations, although there were some extremes that made very sorry reading and showed the potential for exploitation. One receptionist was alone on the desk of a seven-practitioner practice, whereas others listed tasks they were expected to perform such as re-upholster- ing the dental chair and painting and decorating the practice. These are the extremes and most employers are much more reasonable about staffing levels and have practice maintenance tasks performed professionally.

Our biggest concern is linked to age distribution, as our results show declining numbers of receptionists from 31 to retirement. We recognise that we need to repeat the study at regular intervals to see the ongoing picture, but we know from our own membership renewal follow-ups, that the majority of members who don't renew have left dentistry. This represents something of a 'skills drain' with valuable skills and experience being lost to dental employers. We need to find ways to recruit and retain high quality staff to replace a retiring work force, rather scraping the barrel to replace a disillusioned workforce leaving dentistry for better employment deals elsewhere.

It would be valuable to establish through a future survey how many receptionists are the only or primary wage earners in their household. We believe this would show there has been a shift from the times when many receptionists were part-time workers supplementing the family income. In the survey section that explored average hours per week worked, we were surprised to see that a significant number of responders worked full time plus extra hours - in some extreme cases as many as 50 hours per week. The section of the survey that produced the closest match to our expectations was additional duties. Here we found that there is a significant blurring of the line between dental receptionists and dental practice managers. The survey asked receptionists to indicate which of a range of work tasks they performed in addition to the traditional receptionist job description. Here the survey proved additional duties of a management or supervisory nature to be the norm rather than the exception. This being the case, the loss of these personnel to practices must be very disruptive.

It leads us to wonder what type of training and preparation is given for the performance of such tasks and what type of reward and recognition is received. The survey found that salaries did not match responsibilities or experience, and that work specific training and qualifications were the exception rather than the rule. The BDRA has developed a Green Light Training Guide to show receptionists and their employers where work specific training and qualifications can be found.

With the research in place we are left with a lot more questions to investigate in another survey planned for 2005 after the changes linked to dental nurse registration and Options for Change have come into effect. 